S sciendo

\title{
Doxastic Voluntarism and Self-deception
}

Anthony R. Booth

UNAM, Mexico

Disputatio Vol. 2, No. 22

May 2007

DOI: $10.2478 /$ disp-2007-0003

ISSN: 0873-626X 


\title{
Doxastic voluntarism and self-deception
}

\author{
Anthony R. Booth \\ UNAM, Mexico
}

\begin{abstract}
Direct Doxastic Voluntarism - the notion that we have direct (un-mediated) voluntary control over our beliefs — has widely been held to be false. There are, however, two ways to interpret the impossibility of our having doxastic control: as either a conceptual/logical/metaphysical impossibility or as a psychological impossibility. In this paper I analyse the arguments for (Williams 1973; ScottKakures 1993; Adler 2002) and against (Bennett 1990; Radcliffe 1997) both types of claim and, in particular, evaluate the bearing that putative cases of self-deception have on the arguments in defence of voluntarism about belief. For it would seem that if it is the case that self-induced cases of self-deception are indeed possible, then voluntarism about belief could be true after all. Bennett claims that Williams' argument for the impossibility case proves too much in that if it is successful in ruling out direct doxastic voluntarism, it is also successful in ruling out cases of indirect doxastic voluntarism. If cases of self-deception can also be cases of indirect doxastic voluntarism, then such cases support the argument against the impossibility case. I argue that Bennett is right in claiming that Williams' argument proves too much, that cases of self-deception are indeed also sometimes cases of indirect self-deception and so that they cause genuine trouble for the conceptual impossibility case. However, I also argue that this is the only genuine worry for Williams' argument. I end, while considering whether cases of self-deception can tell us anything about the psychological possibility of direct doxastic control, by suggesting a way of establishing the conceptual impossibility of direct doxastic control that circumvents Bennett's counter-argument.
\end{abstract}

\section{Believe what you will}

Can we believe propositions at will? It seems that palpably we cannot. We do not have the same control over what propositions we believe that we do over what actions we perform. I can make myself act like a fool if I wish to, but I cannot make myself believe that I am a fool in the absence of adequate evidence for it, even if I really desire to or if I

Disputatio, Vol. II, No. 22, May 2007 
have practical reasons for so believing it. For instance, imagine that I offer you 1,000 pounds to believe that I am a giant grasshopper. You may, if you were in dire straits, behave as if I was a grasshopper (duck from my imagined hops) but could you make yourself actually believe it just by an act of will? Our intuitions tell us, it seems, to strongly deny this possibility. As William Alston puts it:

If I were to set out to bring myself into a state of belief that $p$, just by an act of will, I might assert that $p$ with an expression of conviction or dwell favourably on the idea that $p$, or imagine a sentence expressing $p$ emblazoned in the heavens with an angelic chorus in the background intoning the Kyrie of Mozart's Coronation Mass. All this I can do at will, but none of this amounts to taking a belief that $p$ (Alston 1989: 122-123).

This consideration on its own does not indicate that we have absolutely no control over what propositions we believe. All it indicates is that we cannot bring ourselves to believe propositions just by an act of will. For we may indirectly be able to control what propositions we believe. For instance, someone who's heard Pascal's Wager may wish themselves ${ }^{1}$ to believe in God, and may in fact achieve this feat my shutting themselves off from any atheist literature, going to church lots, and putting themselves in the company of zealous priests. But here they have not achieved their end by merely the means of an act of will; rather, they willed themselves to be put in an epistemic situation were they would believe what they had sought to and, again as Alston puts it, we do 'have voluntary control over whether to keep looking for evidence or reasons, and voluntary control over where to look and what steps to take' (Alston 1989: 130). Yet such control is indirect, it requires taking further measures in order to induce the coveted belief(s). In this paper I am only going to consider whether direct doxastic voluntarism is true - i.e. whether we have direct control over what propositions we believe ${ }^{2}$.

It is worth saying a bit more about what direct Doxastic Voluntarism is. For a subject $\mathrm{S}$ to induce himself directly to believe proposition $p$ at time $\mathrm{t}$, it is necessary that $\mathrm{S}$ induces the belief that $p$ immedi-

\footnotetext{
${ }^{1}$ Of course, to what extent we have control over what we desire or intend is also a highly contentious issue, as the Toxin Puzzle may show; see Kavka 1983.

${ }^{2}$ From now on when I refer to Doxastic Voluntarism, unless stated otherwise, I am referring to Direct Doxastic Voluntarism.
} 
ately at t, i.e. in the absence of mediation ('just like that', as it were). Take, for instance, the case of actions over which we are usually held to have direct control. Imagine that I offer you 1,000 pounds for you to raise your arm. Imagine that you need the money and that you do immediately raise your arm. This is a case of immediate inducement because you raised your arm simply by willing it; no mediating steps needed to be taken in order for the feat to be accomplished - you did not get someone else to raise it for you, you did not put yourself into a position where you would suffer unwanted consequences if you did not raise it, for example. However, as Jonathan Bennett remarks in Bennett (1990: 88), there are of course intermediate steps you do take to raise your arm in this scenario- you come to believe that I am going to give you 1,000 pounds if you raise it and you form the intention to raise it. Yet there is something different about these steps in that while they are constitutive parts of what it is to be induced to raise your arm, they are not means you have to take in order to get your arm up. These constitutive steps are simply part of what it is to raise your arm. Nevertheless, there is perhaps a stronger way in which the raising of your arm is mediated. Your arm would not go up if some neural activity in your brain did not take place before or during the event. Jonathan Bennett calls this ontological mediation Bennett (1990: 89): the events of my offering you money and of you raising your arm lie in a causal chain which contains other events in between (like a neuron firing). Bennett contrasts this sort of mediation with motivational mediation, which, he argues, is not what occurs when one wills oneself to raise one's arm. Consider the practical syllogism (ceteris paribus):

(1) Someone has offered me 1,000 pounds to raise my arm.

(2) I desire that I receive 1,000 pounds.

(3) Therefore, I raise my arm.

Although it is the case (I continue to follow Bennett) that neural events are doing mediating work in the causal sequence of events, it is not the case that there is some motivating thought about such events intervening in the above syllogism (the thought 'to get the grand I will have to get my c-fibre to fire in order that I may raise hand, so I am motivated to try to get my c-fibre to fire' does not have to intervene to complete the syllogism). So even though all actions (including 
belief at will) must always be ontologically mediated ${ }^{3}$, some actions (such as the raising of one's arm) are not motivationally mediated. For the rest of this paper I will argue that actions that get you to believe something you want to are always motivationally mediated i.e. that direct doxastic control is impossible ${ }^{4}$.

However, there are two ways in which doxastic control might be impossible: it could be conceptually or logically impossible, or it could be merely psychologically impossible. Indeed our intuitions regarding whether believing at will is impossible have led philosophers to argue that doxastic control is more than just psychologically impossible but conceptually incoherent. Bennett, for instance, writes:

There is indeed something so chokingly unswallowable about the idea of someone's voluntarily coming to believe something that I have to suspect that this is ruled out at a deeper level than the contingent powers of our minds (Bennett 1990: 90).

I will now formulate some of the arguments used to establish the logical impossibility case and argue that they are blocked by appeal to the putative phenomenon of self-deception. I will then evaluate how appeals to the phenomenon of self-deception could be taken as considerations against the psychological impossibility case. I will argue that considerations about self-deception are not successful in refuting the psychological impossibility of doxastic control.

\section{The conceptual impossibility case}

The most cited argument in favour of the conceptual impossibility case for doxastic control belongs to Bernard Williams in Williams 1973. The argument goes as follows:

\footnotetext{
${ }^{3}$ See also Naylor 1985.

${ }^{4}$ In an effort to rescue epistemic deontologism from the threat of being committed to doxastic voluntarism (which is putatively false), some commentators (e.g. Heller 2000) have attempted a compatibilist (in the vein of Frankfurt) account of doxastic agency. However, as Buckareff 2006 has pointed out, even though this account makes room for there being such a thing as epistemic responsibility it, at most, provides us with an account of how indirect doxastic control might be possible. Because I am interested in the question of whether direct doxastic voluntarism is true, I will not pursue this compatibilist line of defence.
} 
If I could acquire a belief at will, I could acquire it whether it was true or not; moreover I would know that I could acquire it whether it was true or not. If in full consciousness I could will to acquire a 'belief' irrespective of its truth, it is unclear that before the event I could seriously think of it as a belief, i.e. as something purporting to represent reality. ... With regard to no belief could I know - or, if all this is to be done in full consciousness, even suspect — that I had acquired it at will. But if I can acquire beliefs at will, I must know that I am able to do this; and could I know that I was capable of this feat, if with regard to every feat of this kind which I had performed I necessarily had to believe that it had not taken place? (Williams 1973: 148)

To paraphrase the argument in a more schematic form:

(1) It is an essential feature of beliefs that they aim at truth.

(2) If I can believe at will then I must, in full consciousness, know that I am able to acquire a belief irrespective of whether or not it is true.

(3) But I could not consider what I had acquired a belief if I had acquired it in the knowledge that I did so irrespective of its truth.

(4) Therefore, I cannot believe at will.

Given the nature of belief there is something conceptually incoherent about the idea that I can believe at will, according to Williams, since the exercise of the will runs afoul of the claim to truth of belief. Jonathan Bennett in Bennett 1994 has convincingly shown that this argument does not go through, however. Bennett makes two separate replies to Williams' argument. Firstly he asks us to consider a community whose members, called the Credamites (remember we are still within the realm of conceptual possibility), are able to make themselves believe at will, although they cannot achieve this with beliefs that would require their other existing beliefs to be radically re-arranged. Importantly, once a Credamite manages to acquire a given belief at will, they forget that this is how they came by it - i.e. they forget that they willed themselves to believe the proposition in question. Now, although this scenario may seem a little far-fetched, there is nothing conceptually incoherent about it. Or, at least, it does not run against any of Williams' demands: it shows that it is conceptually possible (given the nature of belief) to will yourself to believe a proposition at will without knowing that you had acquired that particular belief regardless of its truth - for all the Credamite knows they may have acquired that belief in the face of hard evidence. Fur- 
ther, the scenario does not purport to show that it is coherent to will to believe without knowing that you are able to acquire a (or some) beliefs irrespective of their truth — 'each Credamite knows that he sometimes wills himself to believe something [irrespective of its truth], even though it is never true that he now has a belief which he now remembers having willed himself to acquire' (Bennett 1990: 93).

Yet perhaps this reply is a bit of philosophical pedantry on the part of Bennett, which can be responded to with a bit of philosophical pedantry in turn. All we need do is modify premise (2) to read:

(2*) If I can believe at will then I must, in full consciousness, know that I am able to acquire beliefs irrespective of whether or not they are true and I must be able to know whether I have done this for each individual belief I acquire in this way.

This manoeuvre need not be read as being ad hoc. Take, analogously, the example of raising one's arm: to willingly raise my arm, I must know that I am generally capable of raising it at will but I must also be able to know, each time I do so (or at the very least, some of the times I do so), whether I am exercising that ability. Otherwise how can it make sense to say that I know that I have that ability? If I was not able to know this for at least some instances of my arm raising, I would also not know that I can in fact raise my arm at will generally - for otherwise the times I rose my arm in the past may have just been a product of a nervous twitch over which I had no control, for instance. So, it seems quite fair to say that one cannot generally know that one can $\varphi$, without having the ability to ever know whether one had $\varphi$-ed at t. Going back to the Credamite case, when the Credamite wills himself to believe, does he satisfy what is required by premise (2*)? Surely not if it is built in to the Credamite's belief forming procedure that, upon acquiring the belief, he forgets how he formed it when he formed it by willing it. So although, as the Credamite example shows, one may satisfy what is required by premise (2) without violating what is required by (3), one cannot satisfy what is required by $(2 *)$ without violating $(3)$. Satisfying $(2 *)$ will mean that I will at least sometimes know how I acquired my beliefs, and if I acquired them irrespective of their truth, I can no longer consider what I had acquired a belief. If $(2 *)$ is a necessary condition for believing at will, then the Credamites cannot believe at will. Therefore, one cannot use 
the possibility of their existence as a means to demonstrate the conceptual possibility of doxastic control.

Bennett has a better reply to Williams' argument, however. It starts off with the consideration that mediated (indirect) ways of getting yourself to believe propositions at will are indeed possible. Indirect Doxastic Voluntarism does, indeed, seem true: we may well get ourselves to believe propositions by getting ourselves into epistemic situations where we are forced to believe what we seek to believe (recall the case of the person who wishes to believe in God), by hypnotism, by subconscious subliminal means or by contriving to deceive ourselves. I think the latter case has special significance and I'll say why shortly. In the meantime note that Williams himself acknowledges that these mediated means to get yourself to believe are possible:

However, even if it is granted that there is something necessarily bizarre about the idea of believing at will, just like that, it may be said that there is room for the application of decision to belief by more roundabout routes. For we all know that there are causal factors, unconnected with truth, which can produce belief: hypnotism, drugs, all sorts of things could bring it about that I believe that $p$ (Williams 1973: p. 149).

However, as Bennett notes, Williams' argument rules such cases out. This is because Williams' argument does not rule out cases of direct doxastic voluntarism by appeal to the fact that all such cases require some mediation, but by appeal to the fact that believing at will is believing in some way that does not involve acquiring evidence. So if there are cases of indirect doxastic voluntarism which do not involve acquiring evidence, then they too fall foul of Williams' requirements. Williams' argument thus seems to prove too much; as Bennett puts it, if Williams' argument 'holds against beliefs acquired voluntarily 'just like that' then it holds against beliefs acquired in any way that does not involve gathering evidence.'

\section{Adler's counter-reply}

In his 2002 book Belief's Own Ethics, Jonathan Adler presents a counter-reply to Bennett's reply which I think is worth considering. Adler's counter-reply goes as follows: 'coming to believe or ceasing to believe in clear defiance of one's evidence needs to be accomplished nonconsciously. Indeed this restriction is tacitly made in 
prominent criticisms of Williams' argument' (Adler 2002: 59). But if believing in defiance of one's evidence is accomplished nonconsciously, continues Adler, then we cannot consider such acts of believing products of our will, for they are no longer within our (at least direct) control.

... to the extent that we need to be unaware of or hide from ourselves, or hide from what we are doing, to that extent we weaken the value of control. Though you may still be able to accomplish the same ends - believe the same contents — with these indirect means, your success will be more dependent on resources outside your will (Adler 2002: 64).

Adler's counter-reply thus works against Bennett's contention that Williams' argument proves too much, by denying that indirect ways of believing at will count as instances of voluntarism, i.e. that indirect doxastic control is impossible if it involves believing in defiance of one's evidence. The wannabe believer in God who puts himself in an epistemic situation in order to get himself to believe want he seeks is not ruled out by this restriction, however, as he has consciously sought evidence in order to achieve his end — that he seeks a particular type of evidence and does not seek counter-evidence for his coveted belief is of no consequence here. This type of indirect doxastic control — where a believer merely changes his epistemic situation, i.e. what evidence is available to him - is possible, according to Adler, and, further, is not in breach of the requirements Williams' set out. However, cases where subjects indirectly get themselves to believe in a manner that does not involve seeking evidence - cases such as self-deception, or hypnotism - Adler does not consider to be genuine cases of voluntarism, since they do not involve the subject being fully conscious of their acts, which he takes to be a condition of being able to believe at will. The point is, then, that it is not problematic that Williams' argument proves they do not exist, i.e. that they are not genuine instances of voluntarism. End of counter-reply.

Whilst it is the case that, to be sure, certain cases of subliminal mediation and cases where one is hypnotised or drugged are not cases where the subject is willing himself to believe consciously, it is not clear that certain other such cases might indeed be so. Take for instance an example of the phenomenon of self-deception (I take this from McLaughlin 1988: 31-33). Imagine that there is a departmental meeting in a few months' time that I really wish not to attend but I also feel I 
really ought to attend and I will feel guilty if I do not unless I had an excuse to (for instance that I was mistaken as to when the time of the meeting was). I thus contrive, wilfully and in full consciousness, to deceive myself - knowing that I will forget that I did this because of my busy schedule, I write down the wrong time in my diary (say four p.m. when the meeting is really to be held at eleven a.m.). When, in the future, I read the diary I come to believe that the meeting is at four and so have successfully deceived myself in full consciousness.

Now it may be argued that I'm not in full control (or I'm not fully conscious) of the mediating mechanisms that enabled the act of selfdeception to take place, e.g. the accuracy of my memory. But this point is, really, by the by. For although I may not be in control and be fully conscious of all the means by which I need to achieve an end I may still be in control over whether or not that end gets achieved. For instance, we would want to say that the President of the United States is in control over whether the United States launches a nuclear missile even though he is not at all conscious nor in control of the mediating means by which his order culminates in a bomb exploding; were he to give the order we would still hold him responsible for the bomb going off and we would have no problem in saying that it had been an act of his will. This shows that we can be considered to be in control of what outcomes transpire in certain cases even when we are not fully conscious of the means by which those outcomes are attained $^{5}$. So mediated acts of believing at will in defiance of one's evidence can, after all, be considered genuine acts of indirect doxastic voluntarism. So Bennett's second reply to Williams' argument, that it is too strong in ruling out such cases, stands unscathed.

\footnotetext{
${ }^{5}$ There is, however, a salient difference between this example and cases of selfdeception, in that it is not necessary that the President is not conscious of the means by which his will is realised in order for the mechanism to work. However, other examples easily fit the bill: take driving a car. There may be something about my personality that makes it the case that if I know about all the mechanisms and contraptions that go into making my engine work, I'll be so distracted by paying attention to those details, that whilst driving I will systematically lose control of the car. So I can only exercise my will (say to drive to my aunt's house) if I am not conscious of (at least some of) the means (the inner workings of an engine, for instance) by which I get there. In any case, even if it were the case that only cases of self-deception contained this feature, it would not obviate our being able to ascribe control to someone who was not conscious of the intricacies of the means by which to get their ends, which is all that is needed here.
} 
It might be worth mentioning that a modified way of formulating Williams' argument has been attempted by Dion Scott-Kakures in Scott Kakures 1994. Scott-Kakures argues that believing at will cannot be coherently considered to be intentional action when we consider an intention as something that can guide or direct ('rationalise') action. As he puts it:

I cannot, from my cognitive perspective at $\mathrm{t}$, see my way through to my altered perspective at $t+1$. If this is so, then the intention that I formulate at $\mathrm{t}$ cannot be one by which I govern or monitor my behaviour through to $t+1$. And this means that, since the arrival at the belief state at $t+1$ is ungoverned or unmonitored, my arrival at that belief state cannot count as something I succeeded in willing, as I do when I succeed in directly willing an arm rise (Scott-Kakures 1994: 95).

So, according to Scott-Kakures, there is a 'cognitive fissure' between the belief states at $\mathrm{t}$ and at $\mathrm{t}+1$ because at $\mathrm{t}+1 \mathrm{~S}$ does not believe that S's belief that $p$ is not epistemically justified, but at $\mathrm{t} S$ does believe that S's belief is not epistemically justified (since believing at will means believing for reasons irrespective of the beliefs truth). One cannot then, without paradox, intend to move from $t$ to $t+1$ because:

...the beliefs which generate the intention are incompatible with my believing that $p$. Thus the intention must be abandoned before its satisfaction conditions are realized. If the intention that I formulate must be abandoned before I succeed in bringing about the state of affairs it represents, then that intention cannot be one by which I direct and monitor my activity until success (Scott Kakures 1994: 96).

Thus believing at will is an incoherent notion. The conceptual impossibility argument, modified in this way, can now deal with Bennett's response that it rules out all cases of believing in a way that does not involve acquiring evidence. Under this account, being brain-washed into believing that $p$, for instance, is possible but it is not an intentional action - and it is not a problem to rule out these ways of acquiring beliefs. However, if the argument rules out these sorts of ways of acquiring belief, then it rules out all ways of acquiring beliefs in a way that that does not involve gathering evidence - i.e. all indirect cases of doxastic voluntarism. So if there are cases of indirect voluntarism, cases such as self-induced self-deception, then Bennett's objection, once again, holds. Further, as Dana Radcliffe (Radcliffe 1997) points 
out, the argument suffers from a serious flaw, since it does not follow from the fact that believing at will means believing for reasons other than the truth of a belief, that it must to be the case that if a subject believes at will they will believe that believing $p$ at $\mathrm{t}$ is not epistemically justified. Not believing that my belief that $p$ is justified is not the same as believing that $p$ is not justified (I may later find out that $p$ is in fact, justified). All that believing at will requires is that that the way that I acquire my belief is irrespective of the truth of the belief, and this requirement is not violated if I merely do not believe that my belief that $p$ is justified. However, there is only a 'cognitive fissure' between my belief states a $\mathrm{t}$ and at $\mathrm{t}+1$, if $\mathrm{I}$ believe that $p$ is not justified at $\mathrm{t}$ (since I am aiming to believe that $p$ is justified at $\mathrm{t}+1$ ). If I need not believe this at $\mathrm{t}$ for me to believe at will, then there need not be a tension between my belief states at $t$ and at $t+1$, so there in so necessary incoherence in believing at will.

\section{The psychological impossibility case}

We have so far had to accept that the our being able to believe at will 'just like that' might be a live conceptual possibility, but of course this does not preclude it from being an actual psychological impossibility. It appears most plausible that none of us in this actual world are able to accomplish this feat. However, the voluntarist about belief can enlist the phenomenon of self-deception once again in order to disprove the psychological impossibility case. Needless to say, the psychological impossibility case is not established by the use of argument, rather it is established by appeal to what intuitions we have on the matter - ask yourself, could you really make yourself believe at will? — and then by appeal to empirical result - can anyone else make themselves do this? So the voluntarist can displace the psychological impossibility case by appealing to intuitions that run in the opposite direction and by pointing to cases where beliefs are voluntarily acquired. So self-deception seems to fit the bill for the voluntarist. Most of us, I would say, have at some point in our lives deliberately ignored a piece of salient evidence or deliberately considered something as evidence when palpably it was not in order to hang on to or acquire a belief we have coveted. Here is a well-known example from Sartre:

Take the example of a woman who has consented to go out with a particular man for the first time. She knows very well the intentions which 
the particular man who is speaking to her cherishes regarding her. She knows that it will be necessary sooner or later for her to make a decision. But she does not want to realize the urgency; she concerns herself only with what is respectful and discreet in the attitude of her companion. She restricts this behaviour to what is in the present; she does not wish to read in the phrases which he addresses to her anything other than their explicit meaning. If he says to her, 'I find you so attractive' she disarms this phrase of its sexual background; she attaches to the conversation and to the behaviour of the speaker, the immediate meanings, which she imagines as objective qualities. The man who is speaking to her appears to her sincere and respectable as the table is round or square, as the wall colouring is blue or grey. The qualities thus attached to the person she is listening to are in this way fixed in permanence like that of things. This is because she does not know what she wants....

But then suppose he takes her hand. This act of her companion risks changing the situation by calling for an immediate decision. To leave the hand there is to consent in herself to flirt, to engage herself. To withdraw is to break the troubled and unstable harmony which gives the hour its charm. The aim is to postpone the moment of decision as long as possible. We know what happens next; the young woman leaves her hand there, but she does not notice that she is leaving it. She does not notice because it happens by chance that she is at this moment all intellect. She draws her companion up to the most lofty regions of sentimental speculation; she speaks of Life, of her life, she shows herself in her essential aspect - a personality, a consciousness. And during this time the divorce from body and soul is accomplished; the hand rests inert between the warm hands of her companion - neither consenting nor resisting - a thing. We shall say that this woman is in bad faith (Sartre 1943: 55-56).

Self-deception does seem to be fairly rife phenomenon — for the sake of this paper I have assumed that it is possible - but the question that arises here concerns how we are to interpret what is going on when we deceive ourselves and whether it entails our having direct voluntary control over our beliefs. To appeal to self-deception as a means of disproving the psychological impossibility case, the phenomenon needs to be interpreted in a way that (a) shows how (at least) some instances of self-deception are achieved via no mediatory means and (b) that such acts are conducted deliberately and in full consciousness. The 'missed appointment' example of self-deception is clearly an example where the deception is achieved (albeit consciously and deliberately) in an indirect way (the memory loss, the diary), so it 
cannot be considered an example of direct doxastic control being exercised. But what about Sartre's example? Here the woman ignores the evidence which suggests that her companion wants to engage with her romantically. She does so in order that she may continue to believe that she does not have to make a decision regarding him and does so, it would seem, directly — she does not seem to employ any mechanism to help her achieve her end, except for engaging her mind to other things (but this is just what it means to ignore evidence), so her example satisfies condition (a). Does she ignore the evidence intentionally and consciously (satisfy condition (b)), however? At some level she must, for in order to ignore the evidence she must be able to discern which of her companion's actions count as evidence towards his romantic intent. No doubt, she may reply, were she to have her deception pointed out, that she had no idea that she was doing this, that it had been completely subconscious. There would be nothing wrong with our accepting her interpretation, but, on the other hand there is nothing in the story that would prevent us from interpreting what went on as involving her consciously and deliberately contriving to deceive herself. Or is there? It is feasible for $\mathrm{S}$ to have the ability to hold the beliefs that $p$ (this man has romantic intentions toward me) and that not- $p$ (this man does not have romantic intentions toward me) concurrently at $t$, as long as one of those beliefs is not accessible at $\mathrm{t}$ (or, at least, not accessed at $\mathrm{t}$ ). However, to interpret the woman carrying out this act of self-deception directly, intentionally and in full consciousness, is to interpret the woman as believing that $p$ and that not- $p$ concurrently at $\mathrm{t}$, and that both of the beliefs that $p$, and that not- $p$, are accessible to her at $t$. This is not only psychologically impossible but also conceptually impossible since it leads to Moore's paradox: if believing that $p$ involves taking $p$ to be true, then I cannot believe that $p$ if I also believe not- $p$, as I would no longer be taking $p$ to be true. So it would seem that no act of self deception can be accomplished intentionally and in full consciousness without hiding from oneself (making inaccessible) one of the opposing beliefs - but this involves a mediatory step. One cannot satisfy condition (a) without violating condition (b) and vice versa and, since it is necessary that conditions (a) and (b) are satisfied for cases of self-deception to be cases for direct doxastic voluntarism, it seems that no act of self-deception can establish the psychological possibility of direct doxastic control. Self-deception may indeed, then, involve indirect doxastic control, but it cannot involve direct 
doxastic control (since an act of self-deception cannot be both intentional and unmediated).

Now, these last thoughts may seem a bit quick and, indeed, not dissimilar to the considerations offered by Adler and Scott-Kakures. But let me now try to explain how they differ. I have argued that the biggest worry for Williams' argument against the conceptual possibility of doxastic control is its exclusion of cases of indirect control (where cases of self-deception show this to be a live possibility); I'll say why this is important shortly. I have also argued against Adler's and Scott-Kakures contention that if self-deception (or indeed any case of indirect doxastic control) requires mediation, then it is not, after all, a case of proper agency, i.e. that self-deception cannot be carried out intentionally. So my argument has not been that cases of self-deception fail to be cases of direct doxastic voluntarism because in being mediated they lose intentionality. Rather, the correct way of putting things, I think, is to say that no act of self-deception can be intentional without it also being mediated and that is why a case of selfdeception can never be considered a case of direct doxastic control. Further, because it is also conceptually impossible for self-abnegation to be both intentional and unmediated, in considering whether direct control is psychologically possible, we have learnt why it is also conceptually impossible. Or, this would follow only if all cases of direct control were necessarily always like cases of self-deception. Perhaps, cases such as the Credamite case show how direct control without self-deception is conceptually possible. However, I hope to have shown how the Credamite case is somewhat incoherent and, since I find it inconceivable that there are cases of direct control without self-deception that do not suffer from an incoherence similar to that of the Credamite case, I conclude that direct doxastic control is conceptually impossible ${ }^{6}$.

\section{Concluding remarks}

The trouble with the arguments for the conceptual impossibility of doxastic control is that they rely on the impossibility of indirect control. The possibility of cases of genuine self-deception shows that

\footnotetext{
${ }^{6}$ Notice, further, that this argument leaves open the possibility of our having indirect control over our beliefs.
} 
indirect doxastic control is in fact possible, so the phenomenon of self-deception causes real problems for the conceptual impossibility case. Commentators have mistakenly attempted to claim that cases of indirect control are not really genuine cases of agency in a failed attempt to establish the conceptual impossibility of direct doxastic control. However, they need not have attempted this, since if they had noticed, as I have argued, that this is the only genuine problem for the conceptual impossibility case, i.e. that only cases similar to those of self-deception can be coherently considered cases of voluntarism, then they would have noticed that all forms of direct doxastic control must be necessarily mediated, that direct doxastic voluntarism, conceptually speaking, is false.

Anthony R. Booth Universidad Nacional Autónoma de México (UNAM) Instituto de Investigaciones Filosóficas Cto. Mario de la Cueva s/n Cd. Universitaria, Coyoacán México D.F. 01000 arbooth@fastmail.fm

\section{References}

Adler, J. 2002. Belief's Own Ethics. Cambridge, MA: M.I.T. Press.

Alston, W.P. 1989. The Deontological Conception of Epistemic Justification. In Epistemic Justification: Essays in the Theory of Knowledge, ed. by William Alston (Ithaca: Cornell University Press).

Bennett, J. 1990. Why is Belief Involuntary? Analysis 50: 87-107.

Buckareff, A. A. 2006. Hobartian Voluntarism and Epistemic Deontologism. Disputatio II, 21.

Heller, M. 2000. Hobartian Voluntarism: Grounding a Deontological Conception of Epistemological Justification. Pacific Philosophical Quarterly 81: 130-141.

Kavka, G. 1983. The Toxin Puzzle. Analysis 43: 33-36.

McLaughlin, B.P. 1988. Exploring the Possibility of Self-Deception in Belief. In Perspectives on Self Deception, ed. By Brian McLaughlin. Berkeley: California University Press.

Naylor, M-B 1985. Voluntary Belief. Philosophy and Phenomenological Research 45: 427-436.

Radcliffe, D. 1997. Scott-Kakures on Believing at Will. Philosophy and Phenomenological Research 57: 145-151. 
Sartre, J-P. 1943. Being and Nothingness. Translated by Hazel Barnes. London: Routledge, 2003.

Scott-Kakures, D. 1993. On Belief and the Captivity of the Will. Philosophy and Phenomenological Research 53: 77-103.

Williams, B. 1973. Deciding to Believe. In Problems of the Self, ed. by Bernard Williams. Cambridge: Cambridge University Press. 